\title{
Temperamental Characteristics in Adults with Attention-Deficit Hyperactivity Disorder: A Comparison with Bipolar Disorder and Healthy Control Groups
}

\author{
Suat Ekinci ${ }^{1}$, Kadir Özdel ${ }^{\otimes}$, Bedriye Öncü ${ }^{3}$, Burçin Çolak $^{3}$, Hasan Kandemir ${ }^{4}$ and Saynur Canat ${ }^{3}$ \\ 'Department of Psychiatry, Balikli Rum Hospital, Istanbul, Turkey \\ 2Department of Psychiatry, Diskapi Research and Training Hospital, Ankara, Turkey \\ ${ }^{3}$ Department of Psychiatry, Ankara University, Ankara, Turkey \\ ${ }^{4}$ Department of Psychiatry, Harran University, Şanlıurfa, Turkey
}

\begin{abstract}
Objective To date, the affective temperamental characteristics of adults with attention-deficit hyperactivity disorder (ADHD) have not been studied. The aim of this study is to explore those temperamental characteristics for adults diagnosed with ADHD as measured by the TEMPS-A and then to compare those results with results for individuals diagnosed with bipolar disorder (BD) and with healthy controls.

Methods Forty adults with $\mathrm{ADHD}, 40$ patients with $\mathrm{BD}$, and 40 healthy controls were enrolled in this study. The groups were matched by age and gender. All patients were assessed using the Structured Clinical Interview for DSM-IV Axis I Disorders (SCID I), the Hamilton Depression Rating Scale, the Hamilton Anxiety Rating Scale, the Young Mania Rating Scale and the Wender Utah Rating Scale. Subjects' temperamental characteristics were examined using the Turkish version of the Temperament Evaluation of Memphis, Pisa, Paris and San Diego-auto questionnaire (TEMPS-A).

Results Ten subjects (25\%) in the ADHD group and 15 subjects (30\%) in the bipolar group had at least one dominant temperament. There was no identifiable dominant temperament in the control group. Compared to the control group, the ADHD group scored higher than other groups on all domains of the TEMPS-A: depressive cyclothymic, irritable and anxious. However, the hyperthymic domain was not higher for this group. Adults with ADHD scored higher on the irritable temperament scale as compared to the BD group. The $\mathrm{ADHD}$ and $\mathrm{BD}$ groups had similar mean scores for each of the other four temperaments.

Conclusion The adults diagnosed with ADHD in this study had different temperamental characteristics from the control group, and these temperamental characteristics were similar to those of the bipolar patients. Recognizing the role of temperamental characteristics in adults with ADHD may increase our understanding of ADHD.

Psychiatry Investig 2013;10:137-142
\end{abstract}

Key Words Adult, Attention deficit-hyperactivity disorder, Temperament, Bipolar disorder.

\section{INTRODUCTION}

Attention Deficit-Hyperactivity Disorder (ADHD) is a chronic, developmental psychiatric disorder beginning in childhood and continuing into adulthood with symptoms of inattention, impulsivity and hyperactivity. This disorder can lead

Received: August 14, 2012 Revised: December 3, 2012

Accepted: January 15, 2013 Available online: May 30, 2013

$\triangle$ Correspondence: Kadir Özdel, MD

Department of Psychiatry, Ankara Diskapi Research and Training Hospital, Psychiatry Clinic, Ankara 06110, Turkey

Tel: +90-50-5400-3577, Fax: +90-31-2596-2977

E-mail:kadirozdel@gmail.com

(a) This is an Open Access article distributed under the terms of the Creative Commons Attribution Non-Commercial License (http://creativecommons.org/licenses/by$\mathrm{nc} / 3.0$ ) which permits unrestricted non-commercial use, distribution, and reproduction in any medium, provided the original work is properly cited. to social and academic problems for some individuals in adulthood. ${ }^{1,2}$ While Childhood prevalence of ADHD varies between 3 and $12 \%$ in the literature, it's prevalence in adulthood is 4 to $5 \%$ suggesting that we can estimate that up to $50 \%$ of children affected by $\mathrm{ADHD}$ continue to endorse the condition during their adulthood. ${ }^{3}$

H. S. Akiskal conceptualized affective temperaments as precursor phenotypes for the premorbid course of mood disorders on the basis of Kraepelin's dimensional view of manic depressive insanity. Akiskal ${ }^{4}$ suggested that affective temperaments and mood disorders are both genetically transmitted, thereby sharing a common pathophysiological mechanism. Furthermore, some researchers have proposed that temperamental characteristics may be related to the occurrence of mo- 
od disoders ${ }^{5,6}$ and may have a negative effect on prognosis. ${ }^{7}$

Bipolar disorder (BD) comorbidity rates in adults diagnosed with ADHD have been reported to vary between 9.5\% and $27 \%{ }^{8,9}$ Patients with both these disorders are reported to exhibit the onset of BD approximately 5 years earlier, show more depressive and mixed episodes generally respond less well to treatment and have more a more severe course of illness. ${ }^{10}$ Given the high ADHD comorbidity rates in patients with $\mathrm{BD}$ and their relatives, a familial link between these disorders is possible. $^{10}$

Up to now, the affective temperamental characteristics of adults diagnosed with ADHD have not been studied. Studies on the relationship between ADHD and temperamental characteristics have been limited to studies on ADHD in childhood. Prior studies on ADHD in childhood have suggested that temperamental characteristics in childhood may be correlated with anxiety and mood disorders, ${ }^{11,12}$ and may increase the risk of substance abuse. ${ }^{13}$

A high rate of Bipolar Disorder (BD) comorbidity ${ }^{14,15}$ and bipolar symptoms have been found in adults diagnosed with ADHD. ${ }^{16,17}$ This has raised the question of whether these two disorders are clinically similar or biologically overlapping. ${ }^{18}$ It has not yet been established whether specific temperamental characteristics may have effects that are relevant to diagnosis.

Our study questions are: 1) Do adults diagnosed with ADHD show any specific temperamental characteristics when compared to a healthy control group? 2) Do adults diagnosed with ADHD and those diagnosed with Bipolar Disorder show similar temperamental characteristics?

\section{METHODS}

\section{Subjects}

Subjects diagnosed with ADHD and BD were selected from among outpatients of the Ankara University Faculty of Medicine (Ankara) and Etlik Research and Training Hospital (Ankara) Psychiatry clinics. All subjects were older than 17 years of age and were able to read and write. Patients and controls who agreed to participate in the study gave written informed consent.

Forty adults diagnosed with $\mathrm{ADHD}$, and 40 patients diagnosed with BD who had been euthymic for at least 8 weeks, and 40 healthy controls were enrolled in the study. All groups were matched for age and sex.

The psychiatrists (SE, KO, BC) were trained to administer the Structured Clinical Interview for DSM-IV Axis I Disorders (SCID-I), and assessed the patients with this tool. The ADHD group consisted of forty adults who had been diagnosed with ADHD according to the DSM-IV diagnostic criteria and all were under treatment at the Ankara University
Faculty of Medicine, Department of Psychiatry. All patients diagnosed with ADHD were given a second evaluation by a different psychiatrist (BO) who specializes in ADHD. Next, the WURS was administered along with other measurement tools. Since a high proportion of the individuals with ADHD had been diagnosed with comorbid bipolar disorder, only patients who were symptomatically stable before testing were included in the study. All of the participants were under medical treatment for the relevant diagnosis.

The Bipolar Disorder group consisted of forty patients diagnosed with BD according to DSM-IV diagnostic criteria who had also been euthymic for at least 8 weeks. Upon assessment, their HAM-D scores were 7 or lower, and their YMRS scores were 5 or lower. Only patients who met the criteria for bipolar type-I were included in this study.

Healthy controls were chosen from among people with no current or past axis I psychiatric disorder according to DSMIV criteria, all were 17 or older, and all were able to read and write. This group of subjects was gathered from among hospital employees and their acquaintances. The Ethics Committee of the Ankara University Faculty of Medicine approved this study.

\section{Instruments}

\section{The Structured Clinical Interview for DSM-IV Axis I Disorders (SCID I)}

The SCID-I is a semi-structured interview developed to diagnose DSM-IV Axis I disorders and must be administered by a trained interviewer. ${ }^{19}$ It consists of six modules and takes 25-50 minutes to complete. The Turkish version of the SCIDI has been shown to be a reliable and valid instrument. ${ }^{20}$

The Temperament Evaluation of Memphis, Pisa, Paris and San Diego-Autoquestionnaire (TEMPS-A)

The TEMPS-A developed by Akiskal et al. ${ }^{21}$ is a yes-or-no type self-report questionnaire designed to measure affective temperamental traits, present over the course of a person's entire life. The Turkish version of TEMPS-A is used to identify dominant affective temperament and to assess the mean scores of affective temperament subtypes. The original scale consists of 109 items for males and 110 items for females. The Turkish version inquires about lifelong behavior patterns and consists of 99 items to define 5 temperament subtypes: depressive, hyperthymic, irritable, cyclothymic and anxious. The Turkish version of the TEMPS-A has been shown to be a reliable and valid instument. ${ }^{22}$

\section{The Wender-Utah Rating Scale (WURS)}

The WURS was developed for adults diagnosed with 
ADHD to assess ADHD symptoms in childhood. ${ }^{23}$ On this self report Likert scale each item is rated between ' 0 ' and ' 4 ' (0: none, 4 : extreme), and a score of 46 or higher establishes an ADHD diagnosis in childhood. The Turkish form of WURS has been shown to be a reliable and valid instrument and the cutoff score for the Turkish version was set at 36 points or higher. When a person scores 36 or higher, the sensitivity and specificity of the scale is $82.5 \%$ and $90.8 \%$, respectively. ${ }^{24}$

\section{The Hamilton Depression Rating Scale (HAM-D)}

HAM-D is a 17 item scale administered by an interviewer measuring the severity of depression symptoms within the past week. ${ }^{25}$ The Turkish version of the HAM-D has been shown to be a reliable and valid instrument. ${ }^{26}$

\section{The Hamilton Anxiety Rating Scale (HAM-A)}

The HAM-A is a 13 item scale administered by an interviewer that measures the severity of general anxiety. ${ }^{27}$ Symptom severity is rated between 0 and 4 . The original test was developed by Hamilton. The Turkish version of HAM-D has been shown to be a reliable and valid instrument. ${ }^{28}$

\section{The Young Mania Rating Scale (YMRS)}

YMRS is an 11 item scale administered by an interviewer to measure the severity of manic symptoms..$^{29}$ It was adapted into Turkish and its Turkish reliability and validity study was published in 2001. ${ }^{30}$

\section{Statistical analysis}

Descriptive statistical analyses were done where appropriate. In order to determine group differences, an analysis of variance (ANOVA) was applied to continuous variables $(\alpha=0.05)$. Pairwise comparisons were conducted by post hoc Tukey's HSD tests. We used the Statistical Package for Social Sciences (SPSS) for Windows 18.0 program for this statistical analysis.

\section{RESULTS}

These individuals diagnosed with ADHD (mean age: $26.5 \pm$ $8.7,52 \%$ male), $\mathrm{BD}$ (mean age: $25 \pm 4.5,55 \%$ male), and healthy controls (mean age: $28.4 \pm 7.4,57.5 \%$ male), were similar in terms of age, sex and educational background (Table 1).

Twenty patients (50\%) in the ADHD group were diagnosed with a comorbid mood disorder. Nine (22.5\%) with major depression, 9 (22.5\%) with bipolar disorder and 2 (5\%) with dysthymic disorder. Nine patients in the ADHD group (22.5\%) were diagnosed with generalized anxiety disorder, 3 (7.5\%) with panic disorder, 3 (7.5\%) with obsessive-compulsive disorder, 1 (2.5\%) with somatoform disorder, 6 (15\%) with alcohol abuse, and 3 (7.5\%) with comorbid substance abuse.

In the $\mathrm{BD}$ group, 1 patient (2.5\%) was diagnosed with comorbid panic disorder, 1 (2.5\%) with obsessive-compulsive disorder and 2 patients (5\%) with social phobia.

The mean HAM-D, HAM-A and WURS scores of the adults with ADHD were significantly higher when compared to the $\mathrm{BD}$ group and the healthy control group (Table 1). The YMRS scores of all the groups were similar. While the mean HAM-A, and WURS scores of the BD group were significantly higher than those for healthy controls, the mean HAM-D and YMRS scores were similar for both groups.

\section{Temperamental characteristics}

In the ADHD group, 10 patients (25\%) showed at least one dominant temperament ( 2 irritable, 1 depressive, and 1 hyperthymic temperament). Two patients showed both depressive and anxious temperaments and 1 patient showed both irritable and anxious temperaments. Two patients showed irritable, cyclothymic and anxious temperament characteristics whereas 1 patient showed 4 dominant temperaments (depressive, cyclothymic, irritable, and anxious).

In the $\mathrm{BD}$ group, fifteen patients (37.5\%) showed at least 1

Table 1. Demographic characteristics and comparison of HAM-D, HAM-A, YMRS and WURS scores of adults with attention deficit-hyperactivity disorder, bipolar disorder and healthy control groups

\begin{tabular}{|c|c|c|c|c|c|c|}
\hline & \multirow{2}{*}{$\begin{array}{c}\mathrm{ADHD}(\mathrm{N}=40) \\
\text { mean } \pm \mathrm{SD}\end{array}$} & \multirow{2}{*}{$\begin{array}{c}\mathrm{BD}(\mathrm{N}=40) \\
\text { mean } \pm \mathrm{SD}\end{array}$} & \multirow{2}{*}{$\begin{array}{c}\text { Control }(\mathrm{N}=40) \\
\text { mean } \pm \mathrm{SD}\end{array}$} & \multicolumn{2}{|c|}{ One way ANOVA } & \multirow{2}{*}{ Post hoc Tukey HSD test } \\
\hline & & & & F value & $\mathrm{p}$ value & \\
\hline Age & $26.5 \pm 8.71$ & $25 \pm 4.56$ & $28.4 \pm 7.44$ & 2.27 & 0.10 & \\
\hline Sex (male) & $21(52 \%)$ & $22(55 \%)$ & $23(57.5 \%)$ & $0.20^{*}$ & 0.22 & \\
\hline Education (yrs) & $11.68 \pm 2.21$ & $12.63 \pm 2.12$ & $12.05 \pm 3$ & 1.49 & 0.90 & \\
\hline HAM-D & $13.58 \pm 6.69$ & $2.0 \pm 1.72$ & $1.27 \pm 1.51$ & 110.05 & $<0.001$ & $\mathrm{ADHD}>\mathrm{BD}=$ Control \\
\hline HAM-A & $14.25 \pm 8.69$ & $4.38 \pm 2.70$ & $1.40 \pm 1.50$ & 63.58 & $<0.001$ & $\mathrm{ADHD}>\mathrm{BD}>$ Control \\
\hline YMRS & $1.13 \pm 3.09$ & $0.45 \pm 1.03$ & $0.15 \pm 0.66$ & 2.70 & 0.71 & \\
\hline WURS & $46.65 \pm 19.81$ & $28.55 \pm 20.55$ & $10.93 \pm 7.51$ & 43.93 & $<0.001$ & $\mathrm{ADHD}>\mathrm{BD}>$ Control \\
\hline
\end{tabular}

*chi-square $\left(\chi^{2}\right),{ }^{\dagger}$ denotes no significant difference; > denotes significantly higher score. HAM-D: Hamilton Depression Rating Scale, ADHD: attention deficit-hyperactivity disorder group, HAM-A: Hamilton Anxiety Rating Scale, BD: bipolar disorder group, YMRS: Young Mania Rating Scale, Control: healthy control group, WURS: Wender-Utah Rating Scale, ANOVA: analysis of variance 
dominant temperament. Six showed depressive, 2 showed anxious, 2 showed depressive and cyclothymic, 1 showed depressive and anxious, 1 showed depressive and irritable, and 1 showed hyperthymic and anxious temperament characteristics. We found 3 dominant temperament characteristics depressive, cyclothymic and anxious in 1 patient, and 4 dominant temperament characteristics depressive, cyclothymic, irritable and anxious in 1 other patient. No dominant temperament was identified in the control group.

When we compared the scores of the temperament scale subgroup (TEMPS-A), there was no identifiable difference between the groups in terms of hyperthymic temperament [F $(2,117)=2.48, p=0.88]$. However, for depressive temperament $[F$ $(2,117)=22.05, \mathrm{p}<0.001]$, cyclothymic temperament $[\mathrm{F}(2,117)=$ $26.18, \mathrm{p}<0.001]$, irritable temperament $[\mathrm{F}(2,117)=15.41, \mathrm{p}<$ $0.001]$ and anxious temperament $[\mathrm{F}(2,117)=18.79, \mathrm{p}<0.001]$ the scores showed significant statistical differences between the groups. Post hoc analysis (Tukey's HSD) showed that depressive, cyclothymic, irritable and anxious temperament scores were significantly higher in the ADHD group than in the control group (Table 2).

When we compared ADHD and BD groups by post hoc analysis (Tukey's HSD); irritable temperament sub-scores were significantly higher in the ADHD group. There was no statistically significant difference for the other temperaments (Table 2).

Compared to the control group with a post hoc analysis (Tukey's HSD); depressive, cyclothymic, irritable and anxious temperament sub-scores were significantly higher statistically in the BD group (Table 2).

\section{Temperamental characteristics of the ADHD group without a comorbid mood disorder}

Twenty patients (50\%) in the ADHD group were not diagnosed with a comorbid mood disorder. Temperament scale scores of the ADHD group without a concurrent mood disorder $(\mathrm{MD})$ are compared to those of the BD and the control groups on Table 3.

Eleven patients (55\%) from the ADHD group without comorbid mood disorder MD were male. Their mean age was $26.2 \pm 8.57$. There was no statistically significant difference among the three groups in terms of age $[F(2,97)=2.59, \mathrm{p}=$ $0.80)$, and sex $\left(\chi^{2}=0.61, p=0.97\right)$. In addition, we performed a Mann Whitney U test to compare the two groups, ADHD with or without comorbid $\mathrm{BD}$, and the analysis revealed that there was no significant difference between the two groups in terms of their mean temperament scores.

When we compared the scores of the temperament scale ADHD subgroup (TEMPS-A) without MD, the BD and the control groups; there was no difference among the groups in relation to hyperthymic temperament characteristics [F (2, $97)=1.85, \mathrm{p}=0.16]$. However, the depressive temperament $[\mathrm{F}$ $(2,97)=20.75, \mathrm{p}<0.001]$, cyclothymic temperament $[\mathrm{F}(2$, $97)=18.50, \mathrm{p}<0.001]$, irritable temperament $[\mathrm{F}(2,97)=7.97$, $\mathrm{p}<0.001]$ and anxious temperament $[\mathrm{F}(2,97)=7.97, \mathrm{p}<0.001]$ scores were statistically significantly different between the

Table 2. A comparison of the scores of the temperament subtypes between study groups

\begin{tabular}{|c|c|c|c|c|c|c|}
\hline \multirow{2}{*}{ Temperament } & \multirow{2}{*}{$\begin{array}{c}\mathrm{ADHD}(\mathrm{N}=40) \\
\text { mean } \pm \mathrm{SD}\end{array}$} & \multirow{2}{*}{$\begin{array}{c}\mathrm{BD}(\mathrm{N}=40) \\
\text { mean } \pm \mathrm{SD}\end{array}$} & \multirow{2}{*}{$\begin{array}{c}\text { Control }(\mathrm{N}=40) \\
\text { mean } \pm \mathrm{SD}\end{array}$} & \multicolumn{2}{|c|}{ One way ANOVA } & \multirow{2}{*}{ Post hoc Tukey HSD test* } \\
\hline & & & & F value & $\mathrm{p}$ value & \\
\hline Depressive & $7.30 \pm 3.96$ & $8.50 \pm 5.02$ & $3.08 \pm 1.83$ & 22.05 & $<0.001$ & $\mathrm{ADHD}=\mathrm{BD}>$ Control \\
\hline Cyclothymic & $11.38 \pm 4.99$ & $10.48 \pm 5.72$ & $4.15 \pm 3.62$ & 26.18 & $<0.001$ & $\mathrm{ADHD}=\mathrm{BD}>$ Control \\
\hline Hyperthymic & $11.03 \pm 4.09$ & $8.73 \pm 5.04$ & $9.70 \pm 4.69$ & 2.48 & 0.88 & \\
\hline Irritable & $7.05 \pm 4.46$ & $4.93 \pm 4.24$ & $2.30 \pm 2.48$ & 15.41 & $<0.001$ & ADHD $>$ BD $>$ Control \\
\hline Anxious & $9.55 \pm 6.21$ & $9.05 \pm 6.39$ & $2.83 \pm 3.19$ & 18.79 & $<0.001$ & $\mathrm{ADHD}=\mathrm{BD}>$ Control \\
\hline
\end{tabular}

*denotes no significant difference; >denotes significantly higher score. ADHD: attention deficiency and hyperactivity disorder, BD: bipolar disorder, ANOVA: analysis of variance, HSD: honestly significant difference

Table 3. A comparison of the temperament scale scores of the ADHD group without major depression, with the bipolar and control groups

\begin{tabular}{|c|c|c|c|c|c|c|}
\hline \multirow{2}{*}{ Temperament } & \multirow{2}{*}{$\begin{array}{c}\mathrm{ADHD}(\mathrm{N}=40) \\
\text { mean } \pm \mathrm{SD}\end{array}$} & \multirow{2}{*}{$\begin{array}{l}\mathrm{BD}(\mathrm{N}=40) \\
\text { mean } \pm \mathrm{SD}\end{array}$} & \multirow{2}{*}{$\begin{array}{c}\text { Control }(\mathrm{N}=40) \\
\text { mean } \pm \mathrm{SD}\end{array}$} & \multicolumn{2}{|c|}{ One way ANOVA } & \multirow{2}{*}{ Post hoc Tukey HSD test* } \\
\hline & & & & F value & $\mathrm{p}$ value & \\
\hline Depressive & $6.80 \pm 3.96$ & $8.50 \pm 5.02$ & $3.08 \pm 1.83$ & 20.75 & $<0.001$ & $\mathrm{ADHD}=\mathrm{BD}>$ Control \\
\hline Cyclothymic & $9.10 \pm 4.76$ & $10.48 \pm 5.72$ & $4.15 \pm 3.62$ & 18.50 & $<0.001$ & $\mathrm{ADHD}=\mathrm{BD}>$ Control \\
\hline Hyperthymic & $11.20 \pm 3.98$ & $8.73 \pm 5.04$ & $9.70 \pm 4.69$ & 1.85 & 0.16 & \\
\hline Irritable & $5.55 \pm 3.70$ & $4.93 \pm 4.24$ & $2.30 \pm 2.48$ & 7.97 & $<0.001$ & $\mathrm{ADHD}=\mathrm{BD}>$ Control \\
\hline Anxious & $8.60 \pm 5.31$ & $9.05 \pm 6.39$ & $2.83 \pm 3.19$ & 17.04 & $<0.001$ & $\mathrm{ADHD}=\mathrm{BD}>$ Control \\
\hline
\end{tabular}

*denotes no significant difference; >denotes significantly higher score. ADHD: attention deficiency and hyperactivity disorder, BD: bipolar disorder, ANOVA: analysis of variance, HSD: honestly significant difference 
groups. Post hoc analysis (Tukey's HSD) showed that depressive, cyclothymic, irritable and anxious temperament scores were statistically significantly higher in the ADHD group than in the control group (Table 3).

When we compared the ADHD and BD groups by post hoc analysis (Tukey's HSD); there was no statistically significant difference for any of the temperament subscale scores (Table 3).

\section{DISCUSSION}

In this study, our aim was to identify the temperamental characteristics of adults diagnosed with ADHD and to compare their temperamental characteristics with those of patients diagnosed with bipolar disorder. To our knowledge, this is the first study investigating affective temperaments in adults diagnosed with ADHD.

All temperament scores (depressive, cyclothymic, irritable, and anxious) except for hyperthymic temperament were higher in patients diagnosed with $\mathrm{ADHD}$ and $\mathrm{BD}$ as compared to the healthy controls. The hyperthymic temperament scores of patients with $\mathrm{ADHD}, \mathrm{BD}$ and controls were similar. The most common dominant temperament was irritable temperament for the ADHD group ( $\mathrm{n}=6)$ and depressive temperament for the BD group $(n=12)$. Our findings for the $B D$ group is not in line with previous studies, which have reported that hyperthymic, cyclothymic and irritable temperaments were prominent in patients with $\mathrm{BD} .{ }^{31,32}$ Brieger et al..$^{33}$ reported that $\mathrm{BD}$ patients presenting with mixed episodes exhibited more depressive and anxious and less hyperthymic dominant temperaments. The lower frequency of a hyperthymic temperament and the higher frequency of depressive and anxious temperaments may be related to episode patterns. Additionally, the mean scores for depressive and anxious temperaments seen in the control group were lower than those seen in normal populations, but this was not the case for other temperaments. ${ }^{34}$ This difference could indicate a significant gap between the scores for the patient and the control groups.

When all patients with ADHD were included in our analyses, the ADHD group scored significantly higher on the irritable temperament scale as compared with the $\mathrm{BD}$ group. All other temperament scores were similar.

Because mood disorders may affect temperamental characteristics, ${ }^{35}$ the same analyses were conducted after excluding all ADHD patients diagnosed with a comorbid mood disorder. Under these conditions the differences on the irritable temperament scale scores disappeared. The similarity we found for "pure" $\mathrm{ADHD}$ and $\mathrm{BD}$ patients' affective temperament scores is noteworthy, because affective temperaments are regarded to be an endophenotype for $\mathrm{BD}$.

Cognitive impairments are not unusual in patients with $\mathrm{BD}^{36,37}$ and comorbidity of ADHD and BD is frequent. ${ }^{89,38,39} \mathrm{It}$ is also true that $\mathrm{ADHD}$ and $\mathrm{BD}$ share many symptoms like irritability and distractibilty. ${ }^{16}$ This common pattern suggests that $\mathrm{ADHD}$ and BD may share a common neurobiological basis. ${ }^{18}$ Our findings tend to support this hypothesis, showing that patients with $\mathrm{BD}$ and $\mathrm{ADHD}$ tend to share similar affective temperament profiles.

These results should be interpreted cautiously. First, our sample size was small and the temperamental characteristics of our $\mathrm{BD}$ group were different from those reported by previous mainstream findings. Second, we did not assess the premorbid personalities of patients diagnosed with $\mathrm{BD}$ and $\mathrm{ADHD}$. Because of this, effects from illness or other residual states at the time of assessment cannot be ruled out. In an effort to overcome this limitation, all subjects were assessed according to DSM-IV criteria during a period of full remission from manic and depressive episodes. Third, the affective temperament subtypes were determined by means of a self-report questionnaire. Fourth, the HAM-D and A scores were significantly higher in the ADHD group, and this could affect their performance on the self-rating scale of the TEMPS. Finally, because for adults diagnosed with ADHD comorbidity is the rule rather than the exception, the sample size of our ADHD group without a comorbid mood disorder was particularly small.

Despite these limitations, this study indicates that it may be valuable to take into account the affective temperamental characteristics of patients with $\mathrm{ADHD}$ and $\mathrm{BD}$ in future studies that consider the clinical distinctions or similarities between these disorders.

Recognizing temperamental characteristics gives us a better understanding of adult ADHD and may help us to develop more accurate definitions of the disorders. In future studies a larger sample size could help to distinguish temperamental characteristics of ADHD subtypes.

\section{REFERENCES}

1. Seidman LJ, Biederman J, Weber W, Hatch M, Faraone SV. Neuropsychological function in adults with attention-deficit hyperactivity disorder. Biol Psychiatry 1998;44:260-268.

2. Ekinci S, Oncu B, Canat S. Adult Attention deficit hyperactivity disorders: comorbidity and functioning. Anadolu psikiyatr de 2011;12:185191.

3. Turkyilmaz E, Yavuz BG, Karamustafalioglu O, Ozer OA, Bakim B. Prevalence of adult attention deficit hyperactivity disorder in the relatives of patients with bipolar disorder. Int J Psychiatry Clin Pract 2012;16: 223-228.

4. Akiskal HS. Toward a temperament-based approach to depression: implications for neurobiologic research. Adv Biochem Psychopharmacol 1995;49:99-112.

5. Hirschfeld RM, Klerman GL, Keller MB, Andreasen NC, Clayton PJ. 
Personality of recovered patients with bipolar affective disorder. J Affect Disord 1986;11:81-89.

6. Cassano GB, Akiskal HS, Musetti L, Perugi G, Soriani A, Mignani V. Psychopathology, temperament, and past course in primary major depressions. 2. Toward a redefinition of bipolarity with a new semi-structured interview for depression. Psychopathology 1989;22:278-288.

7. Angst J, Marneros A. Bipolarity from ancient to modern times: conception, birth and rebirth. J Affect Disord 2001;67:3-19.

8. Nierenberg AA, Miyahara S, Spencer T, Wisniewski SR, Otto MW, Simon N, et al. Clinical and diagnostic implications of lifetime attentiondeficit/hyperactivity disorder comorbidity in adults with bipolar disorder: data from the first 1000 STEP-BD participants. Biol Psychiatry 2005;57:1467-1473.

9. Tamam L, Karakus G, Ozpoyraz N. Comorbidity of adult attentiondeficit hyperactivity disorder and bipolar disorder: prevalence and clinical correlates. Eur Arch Psychiatry Clin Neurosci 2008;258:385-393.

10. Bernardi S, Cortese S, Solanto M, Hollander E, Pallanti S. Bipolar disorder and comorbid attention deficit hyperactivity disorder. A distinct clinical phenotype? Clinical characteristics and temperamental traits. World J Biol Psychiatry 2010;11:656-666.

11. Biederman J, Hirshefeld-Becker DR, Rosenbaum JF, Hérot C, Friedman D, Snidman N, et al. Further evidence of an association between behavioral inhibition and social anxiety in children. Am J Psychiatry 2001;158:1673-1679.

12. Rosenbaum JF, Biederman J, Hirshfeld-Becker DR, Kagan J, Snidman $\mathrm{N}$, Friedman D, et al. A controlled study of behavioral inhibition in children of parents with panic disorder and depression. Am J Psychiatry 2000;157:2002-2010.

13. Krueger RF, Hicks BM, Patrick CJ, Carlson SR, Iacono WG, McGue M. Etiologic connections among substance dependence, antisocial behavior, and personality: modeling the externalizing spectrum. J Abnorm Psychol 2002;111:411-424.

14. Millstein RB, Wilens TE, Biederman J, Spencer TJ. Presenting ADHD symptoms and subtypes in clinically refered adults with ADHD. J Atten Disord 1997;2:159-166.

15. Kessler RC, Adler L, Barkley R, Biederman J, Conners CK, Demler O, et al. The prevalence and correlates of adult ADHD in the United States: results from the National Comorbidity Survey Replication. Am J Psychiatry 2006;163:716-723.

16. Milberger S, Biederman J, Faraone SV, Murphy J, Tsuang MT. Attention deficit hyperactivity disorder and comorbid disorders: issues of overlapping symptoms. Am J Psychiatry 1995;152:1793-1799.

17. Galanter C, Pagar D, Davies M, Davies M, Li W, Carlson GA, et al. $\mathrm{ADHD}$ and manic symptoms: diagnostic and treatment implications. Clin Neurosci Res 2005;5:283-294.

18. Kent L, Craddock N. Is there a relationship between attention deficit hyperactivity disorder and bipolar disorder? J Affect Disord 2003;73: 211-221.

19. First MB, Spitzer RL, Gibbon M, Williams J. Structured Clinical Interview for DSM-IV Axis I Disorders-Patient Edition (SCID-I/P, Version 2.0). New York: Biometrics Research Department, New York State Psychiatric Institute; 1996.

20. Corapciouglu A, Aydemir O, Yildiz M. DSM-IV Structured Clinical Interview for DSM-IV (SCID-IV), Turkish Version (Turkish). Ankara: Hekimler Yayin Birligi; 1999.

21. Mundt C, Freeman HL. Interpersonal Origin and Course of Affective Disorders. In: Akiskal HS, Editor. The Temperamental Foundations of Affective Disorders. London: Gaskell, Royal College of Psychiatrists,
1996, p.3-30.

22. Vahip S, Kesebir S, Alkan M, Yazici O, Akiskal KK, Akiskal HS. Affective temperaments in clinically-well subjects in Turkey: initial psychometric data on the TEMPS-A. J Affect Disord 2005;85:113-125.

23. Ward MF, Wender PH, Reimherr FW. The Wender Utah Rating Scale: an aid in the retrospective diagnosis of childhood attention deficit hyperactivity disorder. Am J Psychiatry 1993;150:885-890.

24. Oncu B, Olmez S. Neuropsychological findings in adults with Attention Deficit and Hyperactivity Disorder. Turk Psikiyatr Derg 2004;15: 41-46.

25. Hamilton M. A rating scale for depression. J Neurol Neurosurg Psychiatry 1960;23:56-62.

26. Akdemir A, Turkcapar MH, Orsel SD, Demirergi N, Dag I, Ozbay MH. Reliability and validity of the Turkish version of the Hamilton Depression Rating Scale. Compr Psychiatry 2001;42:161-165.

27. Hamilton M. The assessment of anxiety states by rating. Br J Med Psychol 1959;32:50-55.

28. Yazici MK, Demir B, Tanriverdi N, Karaagaoglu E, YOLAÇ P. Hamilton anxiety rating scale: inter-rater reliability and validity study. Turk psikiyatr Derg 1998;9:114-117.

29. Young RC, Biggs JT, Ziegler VE, Meyer DA. A rating scale for mania: reliability, validity and sensitivity. Br J Psychiatry 1978;133:429-435.

30. Karadag F, Oral T, Yalcın FA, Erten E. Reliability and validity of Turkish translation of Young Mania Rating Scale. Turk Psikiyatr Derg 2002; 13:107-114.

31. Akiskal HS, Hantouche EG, Bourgeois M, Azorin JM, Sechter D, Allilaire JF, et al. Gender, temperament and the clinical picture in dysphoric mixed mania: findings from a French national study (EPIMAN). J Affect Disord 1998;50:175-186.

32. Kupfer DJ, Frank E, Grochocinski VJ, Cluss PA, Houck PR, Stapf DA. Demographic and clinical characteristics of individuals in a bipolar disorder case registry. J Clin Psychiatry 2002;63:120-125.

33. Brieger P, Roettig S, Ehrt U, Wenzel A, Blöink R, Marneros A. TEMPSA scale in 'mixed' and 'pure' manic episodes: new data and methodological considerations on the relevance of joint anxious-depressive temperament traits. J Affect Disord 2003;73:99-104.

34. Vázquez GH, Tondo L, Mazzarini L, Gonda X. Affective temperaments in general population?: a review and combined analysis from national studies. J Affect Disord 2012;139:18-22.

35. Hirschfeld RM, Klerman GL. Personality attributes and affective disorders. Am J Psychiatry 1979;136:67-70.

36. Senturk V, Goker C, Bilgic A, Olmez S, Tugcu H, Oncu B, et al. Impaired verbal memory and otherwise spared cognition in remitted bipolar patients on monotherapy with lithium or valproate. Bipolar Disord 2007;9(Suppl 1):136-144.

37. Barbosa JG, Rocha NP, Huguet RB, Ferreira RA, Salgado JV, Carvalho LA, et al. Executive dysfunction in euthymic bipolar disorder patients and its association with plasma biomarkers. J Affect Disord 2012;137: 151-155.

38. Kessler RC, Adler L, Barkley R, Biederman J, Conners CK, Demler O, et al. The prevalence and correlates of adult ADHD in the United States: results from the National Comorbidity Survey Replication. Am J Psychiatry 2006;163:716-723.

39. Bond DJ, Hadjipavlou G, Lam RW, McIntyre RS, Beaulieu S, Schaffer A, et al. The Canadian Network for Mood and Anxiety Treatments (CANMAT) task force recommendations for the management of patients with mood disorders and comorbid attention-deficit/hyperactivity disorder. Ann Clin Psychiatry 2012;24:23-37. 